\title{
Household attitudes and knowledge on drinking water enhance water hazards in peri-urban communities in Western Kenya
}

\begin{abstract}
Authors:
Kimongu J. Kioko ${ }^{1}$

John F. Obiri ${ }^{1}$

Affiliations:

${ }^{1}$ Department of Disaster

Management and Sustainable Development, Masinde

Muliro University of Science and Technology, Kenya

Correspondence to:

John Obiri

Email:

jafobiri@gmail.com

Postal address:

PO Box 190-50100,

Kakamega, Kenya

Dates:

Received: 17 May 2012

Accepted: 27 Aug. 2012

Published: 07 Dec. 2012

How to cite this article: Kioko, K.J., \& Obiri, J.F., 2012

'Household attitudes and knowledge on drinking water enhance water hazards in peri-urban communities in Western Kenya', Jàmbá: Journal of Disaster Risk Studies 4(1), Art. \#49, 5 pages. http://dx.doi.org/ 10.4102/jamba.v4i1.49
\end{abstract}

C 2012. The Authors. Licensee: AOSIS OpenJournals. This work is licensed under the Creative Commons Attribution License.
Ensuring safe drinking water remains a big challenge in developing countries where waterborne diseases cause havoc in many communities. A major challenge is limited knowledge, misinformation and attitudes that work against ensuring that drinking water is safe. This study investigated the knowledge, attitudes and practices of peri-urban households in Kakamega Town of Western Kenya, concerning the collection, treatment and storage of drinking water. Alongside this we examined the role of solid waste disposal in water safety. Three hundred and seventy eight households from four residential regions of varying economic levels were randomly sampled in Kakamega Town. Data was collected via questionnaire interviews that incorporated attitude questions based on a Likert scale of $1-5$, and administered to the households and key informants. The results showed most respondents were knowledgeable about ideal methods of water collection, treatment and storage. However, they did not practise them appropriately. Some attitudes among the respondents worked against the ideals of achieving safe drinking water. For instance, many households perceived their drinking water source as safe and did not treat it, even when obtained from open sources like rivers. Further, they preferred to store drinking water in clay pots, because the pots kept the water cold, rather than use the narrownecked containers that limit exposure to contaminants. Also, hand washing with soap was not practised enough in their daily lives to avoid contact with waterborne hazards. We recommend that the government undertake training programmes on drinking water safety that advocate appropriate water use, hygiene and sanitation strategies.

\section{Introduction}

Globally, an estimated 1.7 million people die annually, largely through waterborne diseases caused by poor water quality and lack of basic sanitation and hygiene (Ashbolt 2004; WHO 2012). The most affected are children under five years, particularly in developing countries, who often succumb to the ravages of diarrhoeal diseases (Kosek et al. 2003).

Notwithstanding the above, WHO estimates that over $90 \%$ of diarrhoea cases can be prevented by enhancing the availability of clean water and improving hygiene and sanitation measures. The burden of these diseases is felt most keenly in African countries, especially in the tropical region, which includes Kenya (Kung et al. 2002). Although these diseases have been reported in most of the tropical African countries, the lack of water sanitation as a hazard has not been exhaustively studied, particularly the knowledge and attitudes of local communities towards sanitation measures and their ideals in reducing the hazards (Kosek et al. 2005; Özdemir et al. 2011). For instance, Kenya has experienced recurrent cases of waterborne diseases like cholera (TDN 2007; Wambua, 2008), with morbidity patterns over the last ten years ranking diarrhoea as the fourth priority disease (HSSR 2005). In this Kenyan case, among the most affected regions is the Western Province, notably the districts of Bungoma, Busia and Kakamega (DMO 2003; Onyango \& Angienda 2010). The last district was examined in this study, exploring factors linked to water handling (e.g. water collection, treatment and storage) and sanitation (e.g. waste disposal and pollution alongside rivers). Invariably, the extent of safe water handling was determined by the local people's knowledge and attitudes towards water safety and sanitation (Özdemir et al. 2011). This study therefore examined the knowledge and attitudes of peri-urban communities concerning water safety and sanitation. It further explored the initiatives, such as water treatment, that the communities undertook to enhance Disaster Risk Reduction (DRR) towards outbreaks of waterborne diseases.

\section{Materials and Methods}

This study was undertaken in Kakamega Town, in Kakamega County situated in Western Kenya at latitude $0^{\circ} 15^{\prime} 0^{\prime \prime}$ North, longitude $34^{\circ} 45^{\prime} 0^{\prime \prime}$ East. Six peri-urban residential areas (Lurambi, Kefinco, Milimani, Sichilayi, Amalemba and Maraba) were selected, with households being the unit for sampling. The households' economic status ranged from those that were relatively urban 
to the rural poor that faced challenges of water supply and sanitation. A total of 378 households was sampled using questionnaire interviews. Besides this, key informants from the water companies and officials from the government's Ministry of Public Health and Sanitation were interviewed. The questionnaires sought to investigate the various types of water sources used by households, including the knowledge and attitudes of respondents to issues of water collection, treatment and storage. The attitude questions put to the respondents, were based on a Likert scale of 1-5 (strongly agree to strongly disagree) and anchored on various arguments linked to the management of drinking water. To evaluate the sanitation levels, water points, wells and key rivers in the region (e.g. Isikhu River and its distributaries) were studied to check for incidences of solid waste disposal, open defecation or similar sanitation hazards.

\section{Results and Discussion}

\section{Types of water sources and community perceptions of the water source safety}

Most of the respondents (51\%) obtained their water from open sources (largely rivers and wells), which are prone to contamination. The remaining $49 \%$ obtained water from boreholes $(41 \%)$ and taps $(8 \%)$, which are relatively safer for drinking as they are less exposed (Figure 1).

\section{Choice of water treatment method}

When asked what they felt about the safety standards of the water they used, the results were as indicated in (Figure 1). The highest perception of water being safe was recorded among the well users, of whom $60 \%$ felt their water was not dangerous. In comparison, $50 \%$ of the tap water users and $48 \%$ of borehole users considered their water safe. River water users had the lowest confidence in their water, as only $41 \%$ of them perceived the water as safe. Even though taps are closed water systems, and therefore safer than wells, these results suggest that respondents still perceive wells as safer. This perception could be explained by the respondents' limited knowledge of the pathways of water contaminations. Although the respondents stated that wells had secured seals on top, and therefore should be clean, most did not consider the unseen underground contamination through the rocks and the soils system. Indeed, in the Kakamega region the groundwater table is very high (average water level being 10 $\mathrm{m}$ from the surface) and this poses high risks of seepage of wastes from dump sites and latrines. Besides the underground waste seepage, continuous heavy rains and floods are other common problems that increase contamination of wells and rivers following floods (CDC 2008a; Ochieng 2012).

The respondents were further asked about the water treatment methods they used on the water they perceived unsafe for drinking. The results are given in (Figure 2). Of the river water users, 50\% used chlorination while the remaining 50\% boiled their water. For those using tap water, $12.5 \%$ used boiling, 50\% used chlorination with $37.7 \%$ using filtration. Among the borehole water users $95 \%$ used chlorination and
$5 \%$ filtered their water. Forty percent of the well water users used chlorination and $60 \%$ filtration. Currently, filtration is an increasingly marketed treatment method that is being adopted by thousands of households in Western Kenya through the advocacy of non-governmental organisations like Lifestraw (Cleary 2012). However, the results show that chlorination was still the most widely used drinking water treatment method. This could be because chlorine is easy to acquire and the procedure is simple and takes less time compared to other treatment like boiling. Reports by UNICEF (1999), Hutton et al. (2007) and CDC (2008b) show that improvements in drinking water quality through treatments, such as chlorination at point of use and adequate domestic storage, greatly reduce diarrhoeal incidences. For effective water treatment, the method used should be determined by the source of the water. For example, water from a river may first require filtration to remove turbidity in order to make chlorination effective.

\section{Preference of drinking water storage vessels}

Information was also sought on the type of vessels the households used to store their drinking water. It was found that $33 \%$ of the households used a bucket, $26 \%$ a container

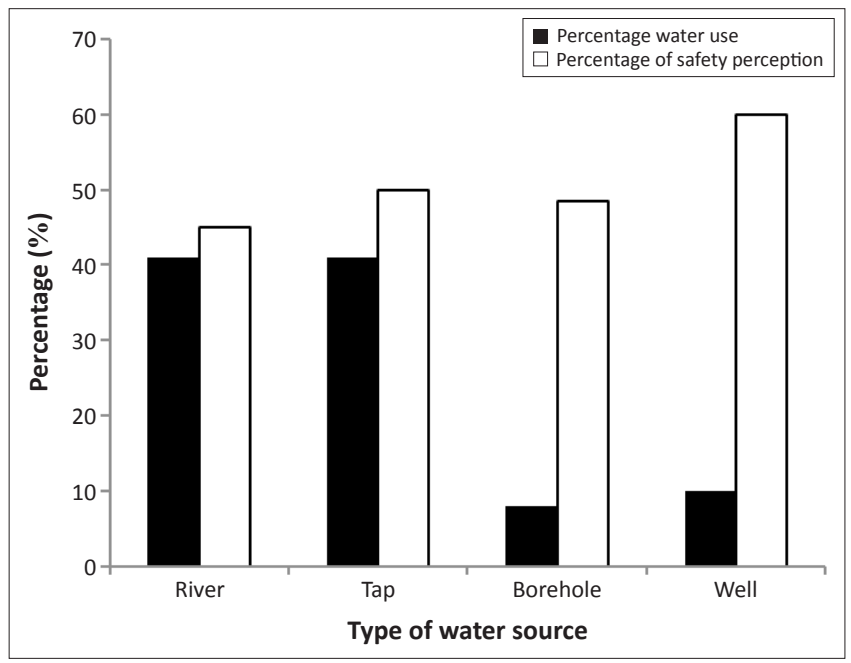

FIGURE 1: The percentage use of water from different sources and their safety levels as perceived by various respondents.

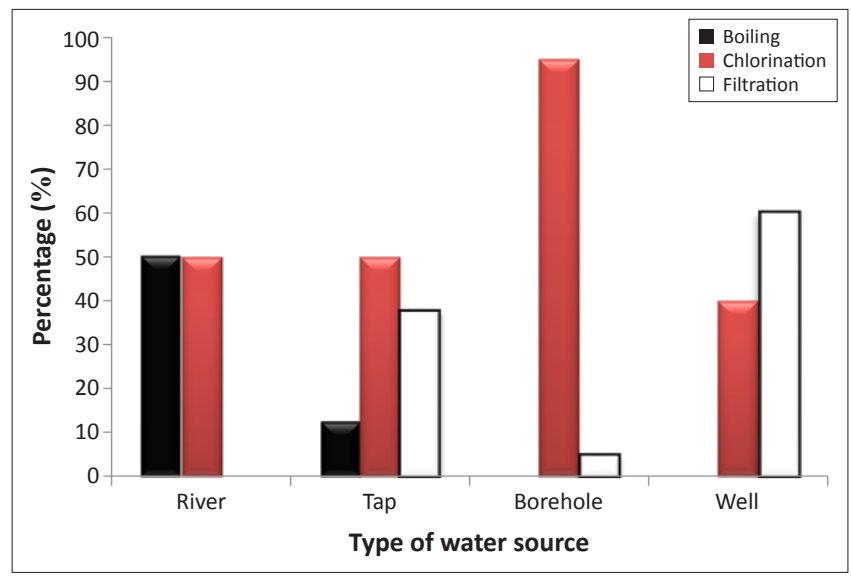

FIGURE 2: Types of water sources and the preferred water treatment methods used by households. 
with a narrow neck, 35\% a clay pot and $6 \%$ a bottle (Figure 3 ). The type of vessel used to store drinking water affects its safety because wide-mouthed containers like buckets and pots, which accounted for $68 \%$ of use, are more prone to contamination because of their large open surface area. Not only were the buckets and pots open, but users often dipped cups and jugs to draw the water, enhancing the risks of dirt. Furthermore, children can easily play with the exposed water. These findings are consistent with other similar research elsewhere that has shown that even drinking water which is safe at the source, is subject to frequent and extensive fecal contamination during collection, storage and use in the home (Wright et al., 2003). Indeed, Crampton (2005) further states that water is vulnerable to contamination by bacteria at many points in its journey from reservoir to mouth.

\section{Factors considered in choice of drinking water storage vessels}

With most of the surveyed population (68\%) using pots and buckets, households were asked why they preferred this storage vessel. Thirty-two percent of them preferred clay pots, as a vessel that keeps the water cool (Figure 4). This factor could be due to the high day temperatures in the area. The ease of drawing water constituted $12 \%$ of the reasons for the use of buckets, with ease of cleaning the container and minimising contamination constituting 11\% respectively. Affordability and other factors constituted $9 \%$ each. Hence, only $25 \%$ of the households considered water safety factors (e.g. easy to cover, minimising contamination, easy to keep safe - Figure 4). The results suggest that community attitudes towards choice of water containers were not based on safety. In fact, the bottles and narrow-necked containers (which offer more guarantee against contamination) could still keep water cool by placing them on the ground or floor inside houses. Indeed, Crampton (2005) showed that the safety of water stored in a narrow-necked vessel was higher than in wide open-mouthed vessels like buckets because contamination through dipping in smaller vessels like cups and jugs was minimised.

\section{Hand washing}

With regards to cleanliness, $87 \%$ reported that they always washed their hands while 13\% only washed them occasionally. Lack of hand washing after toilet use has been linked to contamination of water as bacteria can move from the hands into the water (UNICEF 1999; WHP 2012). To investigate hygienic standards further, respondents were asked to what extent they used water with soap. Sixtythree percent claimed that they always used soap, $21 \%$ used it occasionally and $16 \%$ never used soap. The latter group stated lack of money for buying soap as the reason for not using soap. Though hand washing after toilet use is an important positive hygiene practice, it is important that it is done with soap and running water to ensure that the germs are removed. Indeed, the Hygiene Behavior Change programme by UNICEF (1999) reports that campaigns to promote hand washing with soap have been shown to result in big health gains.

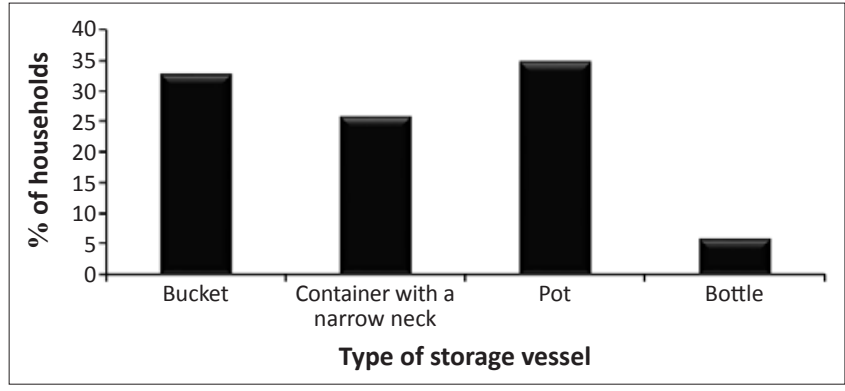

FIGURE 3: Types of water storage vessels and their percentage use.

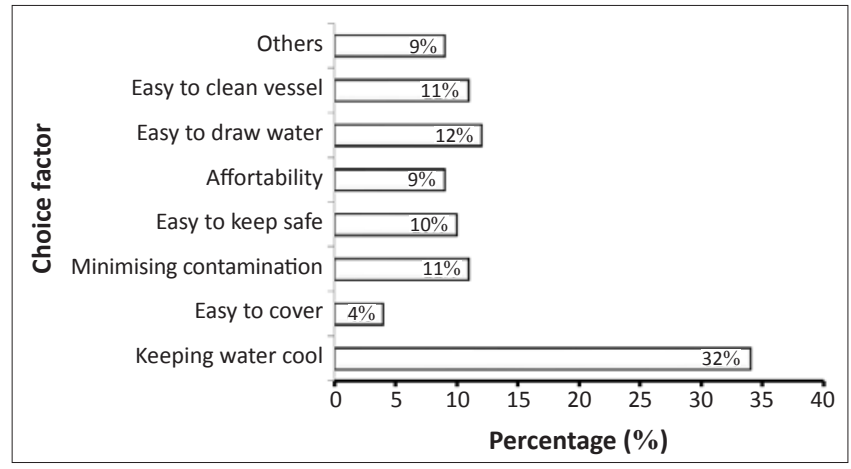

FIGURE 4: Factor determining the choice of household water drinking vessels.

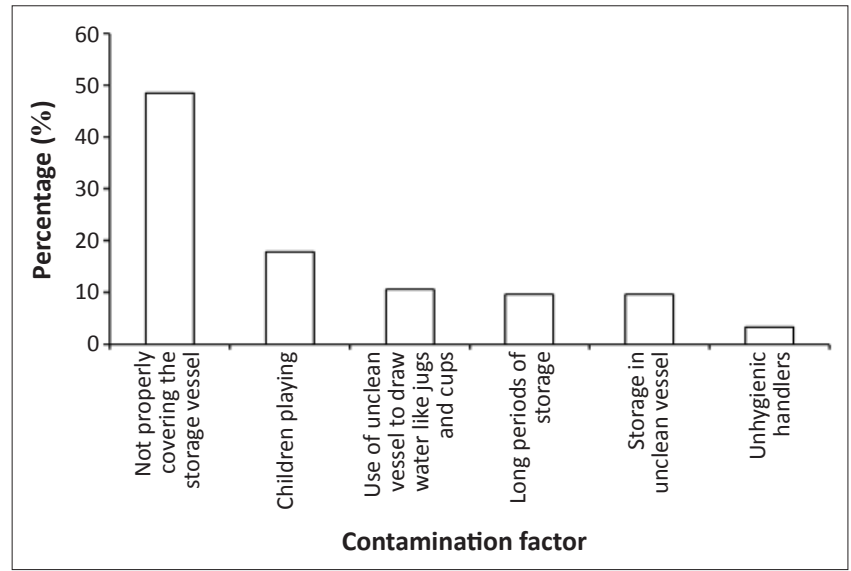

FIGURE 5: Factors perceived to be the key causes of water contamination at household level.

\section{Knowledge of factors causing contamination}

When respondents were asked what they considered the key factors causing contamination of household water, their responses were as in (Figure 5). Forty-nine percent stated the improper covering of storage vessels, $18 \%$ mentioned children, $11 \%$ stated the use of unclean vessels to draw water, $10 \%$ mentioned long water storage periods, $3 \%$ stated the use of unclean containers and another $3 \%$ pointed to unhygienic handlers (Figure 5).

\section{Perceptions of safe water}

To determine community knowledge and perceptions of safe drinking water, the respondents were asked how they determined water to be safe. Forty-two percent used the colour of the water, where clear water was perceived safe for drinking, $24 \%$ used taste, $15 \%$ checked for suspended solids, 
$5 \%$ used temperature of the water, 3\% used information about the source of the water, $8 \%$ used smell, while 3\% stated that water was only safe to drink after boiling (Figure 6). The above responses indicate that the households perceived water to be safe for drinking based on physical parameters. Though water may appear clear, colourless and odourless, it is important to treat the water before drinking and know its source and ensure that it is stored safely. Only 3\% of the respondents seemed to have the correct knowledge (i.e. those who stated boiled water) while $97 \%$ were at risk of drinking unsafe water.

\section{Community contribution to water contamination}

The respondents were also asked whether the community contributed to the contamination of water and responses were as in (Figure 7) 33\% strongly agreed, 48\% agreed, 15\%

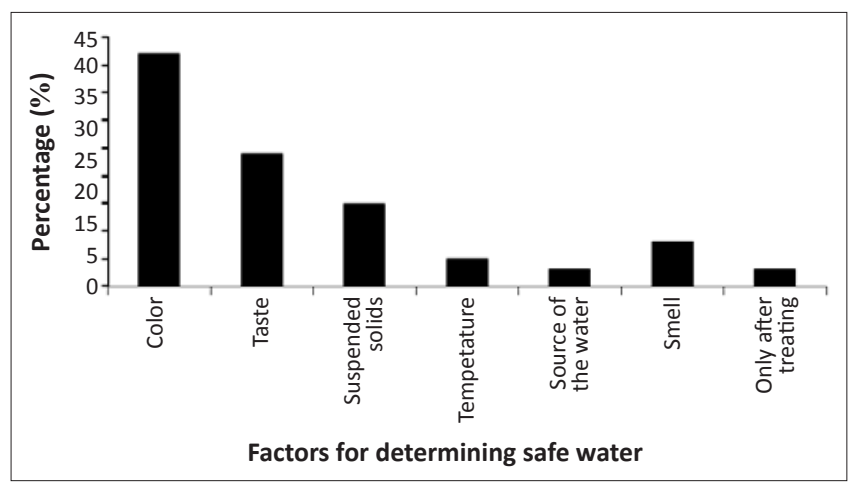

FIGURE 6: Factors used by respondents to determine safe drinking water.

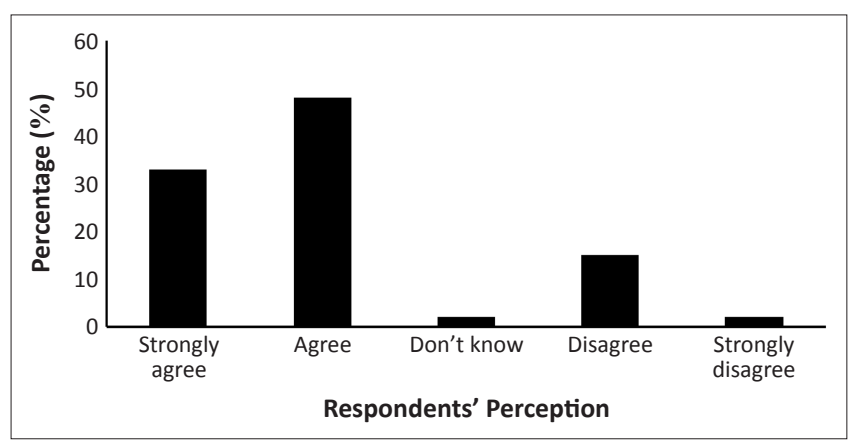

FIGURE 7: Attitudes of respondents towards the claim that the communities caused contamination.

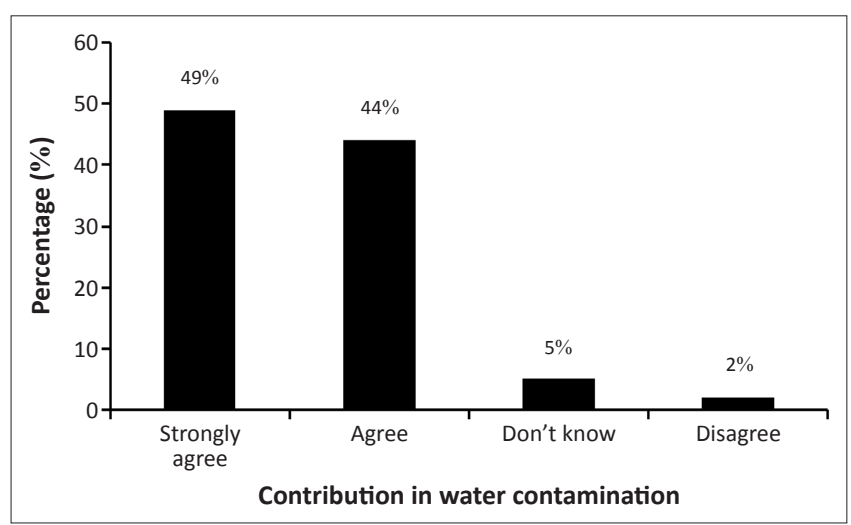

FIGURE 8: Attitude of respondents towards the premise that solid waste disposal methods contribute to water contamination. disagreed while $2 \%$ strongly disagreed that the community contributed to contamination. Those who agreed or strongly agreed (i.e. $81 \%$ ) stated washing of clothes in rivers, bathing in rivers and directing run-off waste to water sources as behaviours that resulted in contamination.

\section{Knowledge on solid waste contamination and water safety}

To determine if there was waste dumping linked to contamination of water sources, households were asked how they disposed of their solid wastes. Seventy-eight percent stated they used dumping pits, $13 \%$ burnt the waste while $9 \%$ said they scattered the waste in farmlands especially banana farms. Solid waste, especially the biodegradable organics, is an important environmental sanitation concern and needs safe disposal. These organic wastes produce leachates, which infiltrate the water in shallow wells, rivers and streams (Mahees et al. 2011). Burning of solid waste may not have a direct negative impact on water, but affect global warming by producing carbon dioxide and is ineffective for material not fully dry.

To determine the attitudes of respondents concerning solid waste and water, they were further asked their opinions on the premise that solid waste disposal caused water contamination. Forty-nine percent strongly agreed that solid waste disposal contaminated water, $44 \%$ merely agreed, $5 \%$ disagreed and $2 \%$ strongly disagreed (Figure 8 ). The results indicate that $93 \%$ of the households (i.e. agree and strongly agree) were aware of the menace of solid waste, including leachate from decomposition of organic material that seeps into water sources. The fact that they continued to dump wastes despite this awareness could be an aspect of poor hygiene behaviour. (WHP 2012; Curtis 2001). This calls for behavioural change on waste and water sanitation management that should be spearheaded by the local government (Jenkins \& Scott 2007).

\section{Conclusion}

The practice of treatment for household water and safe storage can lead to enormous disaster risk reduction in health problems and improvement of livelihoods in any community. The hygiene and sanitation practices of the peri-urban households can greatly affect the quality of drinking water and are a result of culture, knowledge and attitude of the people.

The study revealed that over half of the Kakamega Town peri-urban households did not treat water before drinking, even that from open sources such as rivers. Some of the household treatments were not effective as they were not in line with the anticipated contaminants, e.g. filtration of tap water instead of chlorination. The majority of the households used wide-mouthed containers to store drinking water which are inadequate for limiting contamination. They preferred storage of water in a clay pot (due to its ability to keep water cool) with safety from contamination being a minor consideration. Lack of hand washing with soap 
after toilet visits is still prevalent among some households. Despite being aware that hand washing with soap, especially after visiting the toilet, was a good hygiene practice for maintaining the safety of drinking water, this was not fully practised as expected.

In terms of awareness of drinking water safety, it was found that a majority of the households assumed that water which was clear, colourless and odourless and contained no suspended solids was safe for drinking and therefore it was not treated. Four methods of household water treatment were practised: chlorination, sedimentation, filtration and boiling. However, boiling was rarely practised although it was a vital factor.

Although there was significant knowledge on drinking water safety among the peri-urban households, its application was poor and needed improvement. The same goes for solid waste disposal practices, which were known by the communities but poorly practised.

We recommend that the Kenya government undertake two key measures. First, it should facilitate more training to sensitise communities about household water treatment and safe storage. This should be based on UNICEF's water, sanitation and hygiene strategies. Secondly, it should advocate for hygienic behavioural change concerning open waste disposal, bathing and washing clothes in rivers, among other cultural practices that affect the safety of the drinking water. These factors will go a long way in addressing the local scale of providing safe drinking water for communities as per the millennium development goals.

\section{Acknowledgements}

We thank the Centre of Disaster Management and Humanitarian Assistance of the Masinde Muliro University for providing logistical support in undertaking this research.

\section{Competing interest}

The authors declare that they have no financial or personal relationship(s) which may have inappropriately influenced them in writing this article.

\section{References}

Ashbolt, N., 2004, 'Microbial contamination of drinking water and disease outcomes in developing regions', Toxicology 198, 229-238.

Centre for Disease Control Prevention (CDC), 2008a, 'Flood: Sanitation and Hygiene', viewed 10 May 2012, from emergency.cdc.gov/disasters/floods/pdf/sanitation.pdf.

Centre for Disease Control Prevention (CDC), 2008b, Guidelines for the management of acute diarrhoeal, viewed 8 May 2012, from emergency.cdc.gov/disasters/ hurricanes/pdf/guidelines

Cleary, P., 2012, Life Straw carbon for water program in Kenya. http://vestergaardfrandsen.com/news/press-releases/321-lifestraw-carbon-for-water-programlaunched-in-kenya. Assessed on 6th May 2012.

Crampton, J., 2005, Maintaining Clean Water: Contamination During Water Collection and storage in Addis Ababa, Briefing Note, WaterAid Ethiopia.

Curtis, V., 2001, 'Hygiene: How Myths, Monsters, and Mothers-in-Law can Promote Behaviour Change', Journal of Infection 43, 75-79.

District Medical Office (DMO), 2003, District Medical Officer Report - Busia District Health Strategy work plan, Republic of Kenya, 1999-200.

Health Sector Reform Secretariat (HSSR), 2005, 'The National Health Sector Strategic Plan, Ministry of Health', Republic of Kenya, 1999-2004.

Hutton, G., Haller, L. \& Bartram, J., 2007, 'Global cost-benefit analysis of water supply and sanitation interventions', Journal of Water Health 5, 599-608.

Jenkins, M.W. \& Scott, B., 2007, 'Behavioral indicators of household decision-making and demand for sanitation and potential gains from social marketing in Ghana', Social Science and Medicine 64, 2427-2442.

Kosek, M., Black, R.E. \& Keusch, G., 2005, 'Nutrition and Micronutrients in Tropical Infectious Diseases', in L. Richard, Guerrant, D.H. Walker \& Weller P.F., (eds.), Tropical Infectious Diseases: Principles, Pathogens, and Practice, 2nd ed., Elsevier Health Sciences.

Kosek, M., Bern, C. \& Guerrant, R.L., 2003, 'The global burden of diarrhoeal disease, as estimated from studies published between 1992 and 2000', Bull World Health Organ 81(3), 197-204.

Kung, W.N., Musau, P., Ochieng, A., Wachira, E., Omol, R.T., Rakwar, J., Muthwii, S. Honda, Y., Mudenyo, M., Koyengo G. \& Osaki, Y., 2002, 'Diarrhoea prevalence and risk factors in slums', Journal of National Institute for Public Health 51, 73-76.

Mahees, M.T.M., Sigayoganathan, C. \& Basnayake, B.F.A., 2011, 'Consumption, Solid Waste Generation and Water Pollution in Pinga Oya Catchment area', Tropical Agricultural Research 22, 239-250.

Ochieng, J., 2012, Floods displace 12,000 in Nyanza as Kenya Red Cross donates drugs, The Star, viewed 10 May 2012, from http://www.the-star.co.ke/local/westernnyanza/74174-floods-displace-12000-in-nyanza-as-kenya-red-cross-donates-drugs

Onyango, D.M. \& Angienda, P.O., 2010, 'Epidemiology of Waterborne Diarrhoeal Diseases among Children Aged 6-36 Months Old in Busia - Western Kenya', International Journal of Biological and Life Sciences 6, 92-99.

Özdemir, S., Elliott, M., Brown, J., Nam, P., Hien, V. \& Sobsey, M., 2011, 'Rainwater harvesting practices and attitudes in the Mekong Delta of Vietnam', Journal of Water, Sanitation and Hygiene for Development 1, 171-177.

Tropical Disease News (TDN), 2007, 'Seven People Killed by Cholera in Western Kenya, More Affected', viewed 10 February 2012, from www.medindia.net/news/SevenPeople-Killed-by-Cholera-in-Western-Kenya-More-Affected-30819-1.htm

United Nations Children's Fund (UNICEF), 1999, Towards better programming: a manual for hygiene promotion, Water, Environment and Sanitation Technical Guideline Series No. 6

Wambua, J., 2008, 'Cholera in Kenyan situation a worry', viewed on 7 May 2012, from http://keyscientist.org/talk/viewtopic.php?f $=4 \& t=3$

World Health Organisation (WHO), 2012, Burden of disease and cost-effectiveness estimates, viewed on 7 May 2012, from http://www.who.int/water_sanitation_ health/diseases/burden/en/index.html

World Hygiene Program (WHP), 2012. Fighting preventable diseases with hygiene promotion - the most cost effective public health intervention, viewed on 8 May 2012, from http://whp.org.in/\#Behaviour-Change

Wright, J., Gundry, S. and Conroy L., 2003, 'Household drinking water in developing countries: a systematic review of microbiological contamination between source and point-of-use',Tropical Medicine \& International Health 9, 106-17. 